\title{
The Influence of Weather on the Activity of the Common Shrew
}

\author{
Wpływ pogody na aktywność ryjówki aksamitnej
}

\section{Erkki PANKAKOSKI}

\begin{abstract}
Pankakoski E. 1979: The influence of weather on the activity of the common shrew. Acta theriol., 24, 37: 522-526 [With 1 Table \& 2 Figs.]

Young adult common shrews (Sorex araneus Lin n a e s, 1758) kept in a cage in autumn showed a high level of locomotory activity between 20 and $05 \mathrm{hrs}$. Activity correlated positively with the relative humidity of the air. Activity also tended to increase with the temperature, but this effect was not statistically significant.
\end{abstract}

[Dept. Zool., Univ. Helsinki, P. Rautatiekatu 13, SF-00100 Helsinki 10, Finland.].

\section{INTRODUCTION}

The diel activity of small mammals has often been studied in laboratory experiments (e.g. S a in t G ir o n s, 1966; A s h b y, 1972), while the effect of weather conditions on their activity has been studied by examining trappability in the field (G e n t r y \& O d u m, 1957; G e t z, 1961; M y stkowska \& Sidorowicz, 1961, etc.). The aim of this study was to combine these two approaches and test the effect of the weather on the activity of the common shrew (Sorex araneus Lin$\mathrm{n}$ a e u s, 1758) in a cage experiment.

\section{METHODS}

Three live trapped immature young adult (=summer-born) common shrews were placed together in a glass terrarium $(50 \times 60 \times 30 \mathrm{~cm})$ with a wire net roof. The cage was divided into sections connected by tunnels with a treadle modelled on that of the Longworth trap ( $\mathrm{Cr}$ ow $\mathrm{cr}$ of t, 1957: 92). When a shrew depressed the treadle, an electric circuit was closed, and a pen-stroke was recorded on a revolving drum. Only the impulses from the tunnel leading to the running wheel were counted, because it was used by animals far more frequently than the others. The results thus reflects the general locomotor activity of the shrews.

The shrews were offered an excess of water and food, the latter consisting of a mixture of minced beef or pork, liver, kidneys or heart and hulled grains. They were also fed with live meal beetle larvae (Tenebrio molitor L in na e us, 1758) and fish intestines. The cage was placed in an unwarmed lightly built wooden store-house (not outdoors for fear of vandalism) in Tikkurila $\left(60^{\circ} 17^{\prime} \mathrm{N}\right.$, $25^{\circ} 04^{\prime} \mathrm{E}$ ), Vantaa, southern Finland, under a natural light regime. The experiment was started on 22 October 1971, when the shrews had familiarized themselves with their cage for over one week, and terminated on 20 November in the same year. The results for 4 November were discharged because on that day the food became exhausted. So the material consists of records for 28 complete days in decreasing daylight.

\section{RESULTS}

The number of impulses reflecting the locomotory activity of the common shrew during the study period was on the average $346 /$ day. The activity was greatest around midnight and lowest during the light period (Fig. 1). The time between sunrise and sunset averaged $34 \%$ 
(range 39.4-29.7\%) of the 24-hour period, but the proportion of impulses received during that time was only $13.5 \%$ of the total.

The level of activity increased statistically significantly during the study (analysis of variance between the days: $F=4.41, P<0.001$ ). When the last two days of exceptionally low activity (most probably due to cannibalizing of one shrew by the others) are excluded, the regression coefficient is statistically significant $(b=7.55, P=0.001)$. This increase in

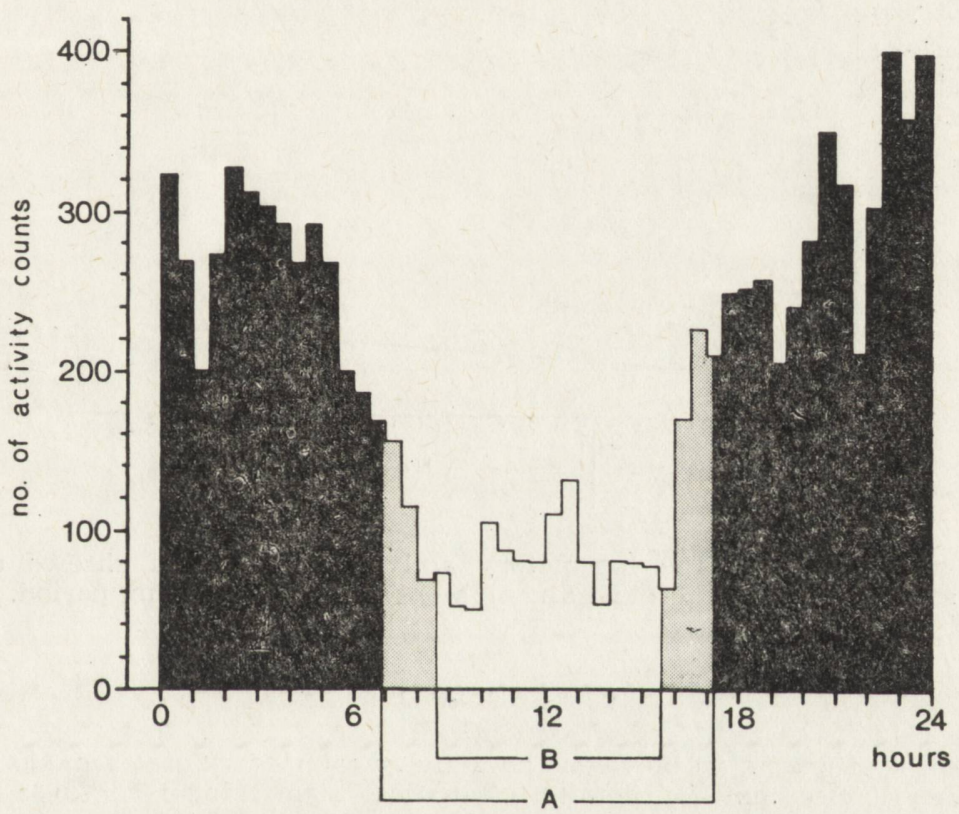

Fig. 1. Diel pattern of locomotory activity shown by three young adult common shrews in autumn.

Fooled results of 28 days given as counts for $30-\min$. periods. $A=$ day length at beginning of study ( 23 Oct.), $B=$ day length at end of study ( 20 Nov.). Black areas $=$ dark period, white area $=$ light period; dotted areas indicate the lengthening of the night during the study period.

the activity was not due to the lengthening of the night, because the activity during the light part of the day also increased significantly (Fig. 2). The difference between the regression lines in Fig. 2 is not statistically significant $(t=0.38, P=0.71)$. The activity during the dark and light periods was positively correlated $(r=+0.508, P=0.006)$.

Correlation analysis was used to study whether the weather conditions in Tikkurila (Source: the Climatological Archive of the Meteorological Institute of Finland) showed any connections with the activity of the shrews. The correlation coefficients were computed in two ways (Table 1):

(1) between the weather parameters and the daily activity counts of the shrews, and

(2) between the weather parameters and the deviation of the daily 


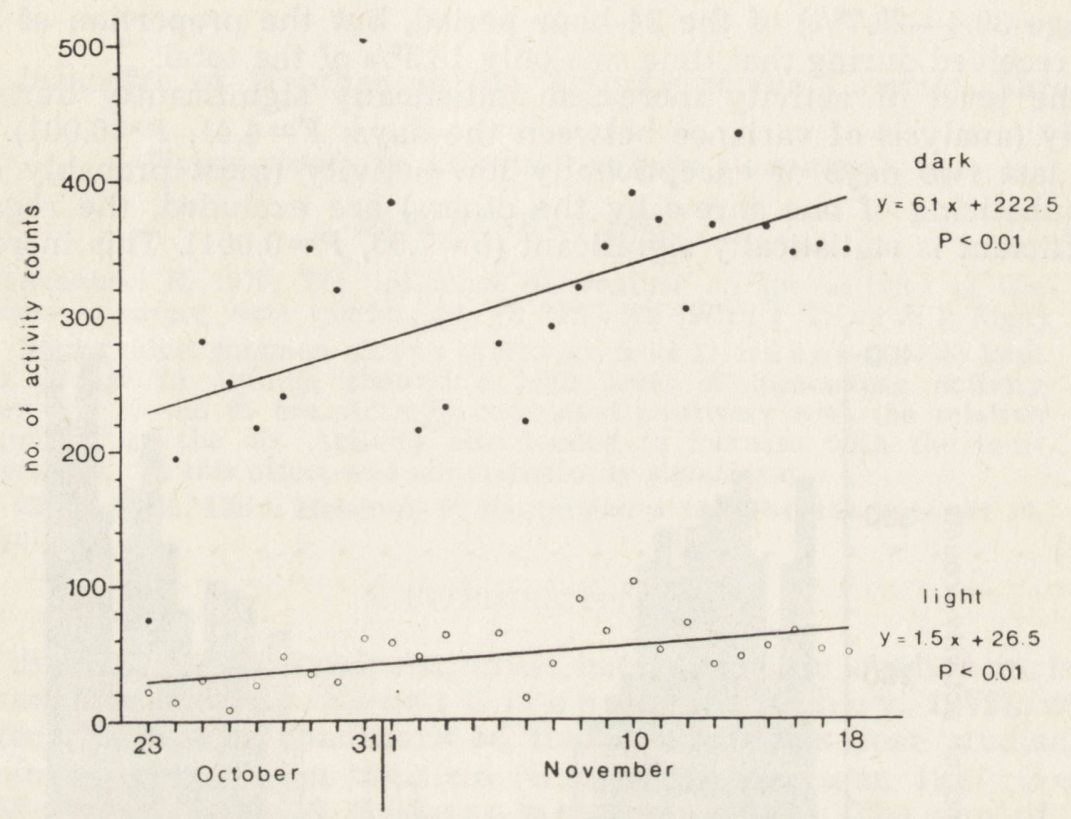

Fig. 2. The increase in the locomotory activity of common shrews during the study period in the dark and light parts of the 24 -hour period.

Table 1

Correlation coefficients ( $r$ ) between the activity counts for Sorex araneus and weather parameters. See text for details. (Statistical significance: ${ }^{*} P<0.05,{ }^{* *} P<0.01$; critical values $(P=0.05)$ in $1: 0.374$, in $2: 0.389)$.

(1)

Correlation with the actual activity counts
(2)

Correlation with the deviations from the regression lines

\section{Temperature}

mean (of $02,08,14$ and $20 \mathrm{hrs}$.)

maximum

$+0.168$

$+0.247$

$+0.011$

minimum

$+0.313$

amplitude

$+0.278$

Relative humidity of the air

mean (of 08, 14 and $20 \mathrm{hrs}$.)

at $08 \mathrm{hrs}$.

at $20 \mathrm{hrs}$.

at $08+20 \mathrm{hrs}$.

Rain

$+0.416^{*}$

$+0.309$

$+0.243$

$+\overline{0.166}$

$\begin{array}{lc}+0.273 & +0.230 \\ +0.358 & +0.301 \\ +0.105 & +0.085 \\ +0.264 & +0.225 \\ +0.272 & +0.221 \\ & \\ +0.529^{* *} & +0.546^{* *} \\ +0.408^{*} & - \\ +0.420^{*} & +0.418^{*} \\ -0.102 & +0.502^{* *} \\ & +0.074\end{array}$


counts from the regression lines (see above). The gradual increase in the activity during the study period was thus eliminated.

The only factor correlating significantly with the locomotor activity of the shrews was the relative humidity of the air outdoors. The activity was greater, when the relative humidity was high. The activity also showed fairly high positive correlations with the maximum daily temperature and the daily temperature amplitude, but these were not statistically significant $(P \geqslant 0.07)$. Rain did not have any effect on the activity, because the animals were kept in a roofed space.

\section{DISCUSSION}

The fairly constant level of high activity recorded in the present study between 20 and $05 \mathrm{hrs}$ agrees moderately well with the results of C rowcroft (1954) and $\mathrm{Buchalczy}$ (1972). According to $\mathrm{Buchalczyk}$ (1972) during the winter the locomotory activity of $S$. araneus shows three activity peaks of nearly the same level (at about $03 \mathrm{hrs}$, between 15 and $18 \mathrm{hrs}$ and around midnight). J a n s k ý \& $\mathrm{H} \mathrm{a-}$ nák (1960) and G ę b c z yński (1969) described a bimodal nocturnal activity pattern. The reason why this was not observed in the present study may be that only locomotory activity was measured, not general activity (i.e. including feeding activity).

A possible explanation for the general increase in the level of activity towards the end of the study period may be that the animals increased their use of the running wheel in response to the gradually sinking autumn temperatures. However, several authors have found that the general activity of shrews is lower in winter than during the warm part of the year (G ębczynski, 1965; B uchalczyk, 1972; Loxto $n$ et al. 1975).

The number of small mammals - shrews included - taken in traps is greatest on warm and cloudy nights (G e n try \& O d u m, 1957; G etz, 1961; Mystkowska \& Sidorowicz 1961 etc.). In the present study the relative humidity of the air was found to correlate positively with the activity of the shrews (see also P e arson, 1959). Although unwarmed, the building in which the experimental cage was housed may have reduced the variation in temperature, and this may have been responsible for the lack of significant correlations between the temperature and activity records.

Acknowledgements: I am indebted to Prof. V. Kanervo, earlier head of the Department of Pest Investigation, and to Mr. A. Myllym\%ki, M. Sc., for providing working facilities at the Agricultural Research Centre, Vantaa.

\section{REFERENCES}

A shby K. R., 1972: Patterns of daily activity in mэmmals. Mэmm. Rev. 1, 7-8: 171-185. Buchalczyk A., 1972: Seasonal variations in the activity of shrews. Acta theriol., 17: 221-243. C r o w c r of t P., 1954: The daily cycle of activity in British shrews. Proc. zool. Soc. Lond., 123: 715-729. C r ow c r of t P., 1957: The life of the shrew. 1-166. London. Gębczynski M., 1965: Season?l and age changes in the metabolism and activity of Sorex araneus Linn a e us, 1758. Acta theriol. 10: 303-331. G entry J. B. \& Odum E. P., 1957: The effect of the weather on the winter activity of old-field rodents. J. Mammal., 
38: 72-77. Getz L. L., 1961: Responses of small mammals to live-traps and weather conditions. Amer. Midl. Nat., 66: 160-170. J a n ský L. \& H a nák V., 1960: Aktivität der Spitzmäuse unter natürlich Bedingungen. Säugetierkdl. Mitt., 8: 55-63. L oxt on R. G., R a ffael1i D. \& B e g on M., 1975: Coprophagy and the diurnal cycle of the common shrew, Sorex araneus. J. Zool., Lond. 177: 449-453. Mystkow ska E. T. \& Sidorowicz J., 1961: Influence of the weather on captures of Micromammalia. II. Insectivora. Acta theriol., 5: 263-273. P e a r s o n O. P. 1959: A traffic survey of Microtus-Reithrodontomys runways. J. Mammal., 40: 169-180. S a int Gir ons M.-C., 1966: Le rythme circadien de l'activité chez les Mammifères Holarctiques. Mém. Mus. National d'Hist. Nat., N. S., A, 40, 3: $101-187$.

Accepted, May 21, 1979. 